\title{
Human Cocaine-Seeking Behavior and its Control by Drug-Associated Stimuli in the Laboratory
}

\author{
Leigh V Panlilio', Sevil Yasar ${ }^{2,3}$, Ro Nemeth-Coslett ${ }^{4}$, Jonathan L Katz ${ }^{5}$, Jack E Henningfield ${ }^{6,7}$, \\ Marcello Solinas', Stephen J Heishman ${ }^{8}$, Charles W Schindler' and Steven R Goldberg*,' \\ 'Preclinical Pharmacology Section, Intramural Research Program, National Institute on Drug Abuse, Baltimore, MD, USA; ${ }^{2}$ Department of \\ Medicine, Division of Geriatric Medicine and Gerontology, Johns Hopkins University School of Medicine, Baltimore, MD, USA; ${ }^{3}$ Behavioral \\ Neurosciences Section, National Institute on Drug Abuse, Baltimore, MD, USA; ${ }^{4}$ Clinical Neurobiology Branch, National Institute on Drug Abuse, \\ Bethesda, MD, USA; ${ }^{5}$ Medication Discovery Branch, National Institute on Drug Abuse, Baltimore, MD, USA; ${ }^{6}$ Department of Psychiatry and \\ Behavioral Sciences, Johns Hopkins University School of Medicine, Baltimore, MD, USA; ${ }^{7}$ Pinney Associates, Bethesda, MD, USA; ${ }^{8}$ Clinical \\ Pharmacology and Therapeutics Branch, National Institute on Drug Abuse, Baltimore, MD, USA
}

\begin{abstract}
Second-order schedules of drug self-administration were developed to incorporate the effects of drug-related environmental stimuli into an animal model of drug abuse, making it more similar to human situations. Ironically, little is known about how human subjects behave under these schedules. In this study, human volunteers with a history of cocaine use worked on a second-order schedule in which every I00th lever response produced an auditory-visual brief stimulus $(2 \mathrm{~s})$. The first stimulus produced after $\mathrm{I} h$ was extended to $10 \mathrm{~s}$ and paired with an intravenous injection of cocaine $(25 \mathrm{mg})$. Up to three injections were allowed per session. In different phases of the experiment, presentation of the brief stimulus was discontinued and/or saline solution (placebo) was injected instead of cocaine. Injections of cocaine were found to maintain responding even when the brief stimulus was not presented. Placebo injections alone did not maintain responding. In contrast, the brief stimulus maintained high levels of responding under placebo conditions, even though selfreports indicated that subjects could clearly discriminate that they were not receiving cocaine. These results demonstrate that drugrelated environmental stimuli can maintain persistent drug seeking during periods of drug unavailability. As this procedure directly measures the effects of stimuli on drug seeking, it may provide a valuable complement to indirect measures, such as self-reports of craving, that are often used with human subjects. The similarity of the response patterns in humans and animals also supports the use of second-order schedules in animals as a valid model of human drug seeking.

Neuropsychopharmacology (2005) 30, 433-443, advance online publication, 10 November 2004; doi:1 0. I038/sj.npp. I 300599
\end{abstract}

Keywords: cocaine; stimulants; self-administration; reinforcement schedule; human; intravenous drug abuse

\section{INTRODUCTION}

Drug addiction is characterized by the excessive behavioral control exerted by drugs and drug-related stimuli (Kelleher, 1975; Kelleher and Goldberg, 1975; O'Brien et al, 1992; Stewart et al, 1984; Wikler, 1973). It has long been evident that forced or voluntary abstinence from drug use (detoxification) in a treatment facility does not constitute a complete remedy for drug addiction. This is true in large

*Correspondence: Dr SR Goldberg, Preclinical Pharmacology Section, Department of Health and Human Services, Intramural Research Program, National Institute on Drug Abuse, NIH, IRP, 5500 Nathan Shock Drive, Baltimore, MD, USA,

Tel: + I 410550 1522, Fax: + | 410550 1648,

E-mail: sgoldber@nih.gov

Received 14 June 2004; revised 21 September 2004; accepted 22 September 2004

Online publication: 28 September 2004 at http://www.acnp.org/citations/ Npp092804040268/default.pdf part because individuals who return to their 'addicted world' are re-exposed to stimuli that were associated with prior episodes of drug use. These stimuli can produce reports of intense drug craving (Childress et al, 1993), and they are described as a trigger of relapse in a large percentage of cases (Shulman, 1989; Wallace, 1989). Thus, it is essential to develop behavioral models that can be used to study the influence of drug-related stimuli and to evaluate medications or behavioral interventions that can reduce their effects.

The intravenous self-administration of drugs by humans and animals in controlled laboratory settings provides such a model. These procedures allow the behavioral and pharmacological variables that influence drug-seeking and drug-taking behavior to be controlled and systematically varied. One specific procedure, the second-order schedule of drug self-administration, has become increasingly popular as an animal model of the influence of environmental stimuli (Everitt and Robbins, 2000; Goldberg et al, 
1975, 1990; Schindler et al, 2002). In a widely used version of this procedure, an environmental stimulus, such as a tone or a light, is briefly presented each time the subject makes a fixed number of responses (eg every 100 pulls on a lever; a fixed-ratio schedule, FR100). After a certain interval of time has passed (eg $1 \mathrm{~h}$ ), the next time the subject fulfills the response requirement, the stimulus is presented along with an injection of cocaine. Studies with non-human primates and rats have shown that the brief stimulus can become a powerful conditioned reinforcer, maintaining responding during long periods when the drug is unavailable (Di Ciano and Everitt, 2003; Kelleher and Goldberg, 1977; Goldberg et al, 1979, 1981; Katz, 1979). Thus, second-order schedules provide a laboratory model of the drug abuse environment, where stimuli guide and maintain the complex sequences of behavior required to obtain, prepare, and ingest the drug.

Although variations of second-order schedules of drug self-administration have been implemented with human subjects in several studies (Heishman et al, 2000; Lamb et al, 1991; Mello et al, 1981, 1990; Mello and Mendelson, 1985), the stimulus manipulations that have proven to be highly informative in second-order drug studies with animals have not been employed with humans. A potential difficulty with studying human drug abuse in the laboratory is that participants may have extremely varied behavioral histories, which can be especially problematic when studying the effects of environmental stimuli on drug use. Although prestudy screening may indicate that all volunteers in a study have previously abused the drug being studied, it cannot be assumed that they will all be influenced by the same environmental stimuli or that they will all be equally sensitive to the manipulation of stimuli. However, if human drug self-administration under second-order schedules in the laboratory closely resembles the behavior of animals under similar conditions, it would indicate that these difficulties can be overcome by using second-order schedules more extensively with humans, and it would provide increased confidence that results obtained under these schedules with animals are indeed relevant to human drug-seeking behavior.

\section{MATERIALS AND METHODS}

\section{Subjects}

Six male volunteers (mean age $=27$ years) resided for up to 7 weeks on the closed research unit at the National Institute on Drug Abuse Intramural Research Program for the duration of the study. The participants were all cigarette smokers and had histories of abuse of a variety of drugs, including opioids, stimulants, and sedatives. All participants reported occasional use of intravenous cocaine within the past month, but were not currently seeking treatment for cocaine abuse or dependence. Except for $1 \mathrm{~h}$ prior to and during experimental sessions, participants were free to smoke their usual brand of cigarettes, but they were not given access to illicit or therapeutically used drugs. They were not permitted to drink caffeinated beverages during sessions or for $12 \mathrm{~h}$ prior to the start of sessions. The study was approved by an Institutional Review Board, and all subjects provided written informed consent according to the guidelines for the protection of human subjects of the US Department of Health and Human Services.

\section{Apparatus and Drug}

Before the study, the safety of the cocaine dose was verified by injecting subjects with three consecutive doses of $25 \mathrm{mg}$ cocaine at 1-h intervals under physician supervision and with constant monitoring of vital signs. Prior to each session during the study, a catheter was inserted into a forearm vein for cocaine and saline vehicle injection under physician supervision. Participants sat in a chair in a test room with access to a radio and magazines. The chair faced an operant test panel equipped with two Lindsley levers and two lights (one green and one red). Two computercontrolled syringe pumps were connected to the catheter and used for injections. One pump delivered $1.0 \mathrm{ml}$ injections of either $25 \mathrm{mg}$ cocaine hydrochloride or saline, which were infused over $10 \mathrm{~s}$. The other pump then flushed the catheter, delivering $0.5 \mathrm{ml}$ of saline over $5 \mathrm{~s}$. Catheter patency during the session was maintained by a gravity-fed dextrose solution infused at a rate of $12 \mathrm{ml} / \mathrm{h}$. To ensure that vital signs were stable prior to cocaine injections, the subject's electrocardiogram was on constant display to a research nurse who sat out of sight of the subject and also monitored the behavior.

\section{Procedure}

Experimental sessions were approximately $3.5 \mathrm{~h}$ in duration and were scheduled 1-3 days apart. The following instructions were read to the subject immediately prior to each session:

'During this test you are free to press the left lever as often as you like. Only presses on the left lever will produce injections; any response on the right lever will have no effect. However, you do not have to press the left lever at all, but you must remain seated, awake, and equipped with the catheter for the duration of the session. During the session, certain lever presses will turn off the green light, turn on the red light, and sound a tone. Other lever presses will result in the light, tone, and an i.v. injection of cocaine or placebo. Doses of cocaine or placebo will remain unchanged throughout an individual session. After each i.v. injection, the lights will go out for about a minute, and the equipment will not operate. If you miss an injection, the lights will also go off for about a minute. When the lights come back, you will need to check your responses on form IVN-5, and then you may continue to press the lever if you like. If you reach an injection limit programmed into the computer, the lights will go off until the program decides it is safe for you to continue. You may end a session or injection immediately by turning off the AC power switch.'

Under the second-order schedule of drug injection, the green stimulus light was turned on at the start of the session. Every 100 pulls on the right lever turned off the green light, turned on the red light, and turned on an audible tone for $2 \mathrm{~s}$. Thus, this brief stimulus complex was presented on a 100-response fixed-ratio schedule (FR100). After a fixed interval of $1 \mathrm{~h}$ (FI $1 \mathrm{~h}$ ) had elapsed since the beginning of the session or since the previous timeout period, the first FR100 component that was completed 
produced the red light and tone for $10 \mathrm{~s}$, along with an injection of either cocaine or saline solution. In standard nomenclature (Goldberg, 1973; Kelleher, 1966), this secondorder schedule of cocaine self-administration would be designated FI $1 \mathrm{~h}$ (FR100:S). For $1 \mathrm{~min}$ following each injection, all stimulus lights were turned off and responses had no scheduled consequences (timeout). Heart rate during the minute before and the minute after each injection was recorded. If the subject did not complete an FR100 component within $10 \mathrm{~min}$ following the end of a 1-h FI, the FI ended without injection, and the green light was turned off for $1 \mathrm{~min}$. Responses on the second lever had no programmed consequences at any time. Sessions were terminated when either three injections had been delivered or $3.5 \mathrm{~h}$ had elapsed. No subject terminated the session by turning off the AC power switch, and all participants selfadministered at least one injection during each session, whether cocaine or saline was available.

During timeout periods, participants were required to rate positive and/or negative effects of the injection on a horizontal, 100-mm visual analog scale (VAS) line (referred to as the IVN-5 form in the instructions to the participants) that was bisected by a vertical line labeled 'neutral (no effect).' The far right of the VAS line was labeled 'strong positive (good effects),' and the far left of the line was labeled 'strong negative (bad effects).' Participants were instructed to place a vertical mark on both the right side of the vertical line to indicate how positive they felt after each injection and on the left side of the vertical line to indicate how 'negative or bad' they felt after each injection. If participants felt no effects from the injection, they were instructed to place a mark on the 'neutral (no effect)' vertical line.

Immediately following each session, two questionnaires were given to the participants to assess the interoceptive effects produced by injections. The first was a short form of the Addiction Research Center Inventory (ARCI; Martin et al, 1971) that consisted of 40 true-false items comprising three scales: MBG (considered a measure of euphoric effects), PCAG (considered a measure of sedation), and LSD (considered a measure of dysphoria, anxiety, restlessness, and perceptual or psychotomimetic changes). The second was the Single-Dose Questionnaire (SDQ; Fraser et al, 1961) comprised of three items: Do you feel the medicine? (yes-no), presence or absence of 13 drug symptoms, and rating of drug liking from 0 (not at all) to 4 (an awful lot). For $1 \mathrm{~h}$ after each session, the number of cigarettes smoked was also recorded. Cigarettes were dispensed and counted by a computer that was activated when the subject pulled a lever five times.

Four conditions were studied. In the 'cocaine-plusstimulus' and 'saline-plus-stimulus conditions', the brief stimulus was presented on an FR100 schedule, and either cocaine or saline, respectively, was delivered when the first FR100 was completed after the lapse of the $1 \mathrm{~h}$ fixed interval. In the 'cocaine no-stimulus' and 'saline no-stimulus' conditions, no brief stimulus was presented during the 1$\mathrm{h}$ FI, but cocaine or saline, respectively, was still delivered and the 10-s red light plus tone stimulus was still presented when the first FR100 was completed after the $1 \mathrm{~h}$ FI had passed. Thus, injections of cocaine or saline were accompanied by $10-s$ stimulus presentations in all conditions.
Each condition was continued until behavior appeared stable for at least three sessions. All six participants were tested under the cocaine-plus-stimulus condition and the saline-plus-stimulus condition, and five were tested under at least one of the other two conditions. In four participants, some conditions were replicated 2-3 times to verify that the effects were repeatable. In total, there were 12 replications of the cocaine with stimulus condition, nine of the saline with stimulus condition, six of the cocaine no-stimulus condition, and five of the saline no-stimulus condition.

\section{Data Analysis}

Data from the last 3 days of each condition were averaged for each subject. In addition, when conditions were replicated within a subject, the data from these replications were averaged. Multi-level analysis with maximum likelihood estimation was performed with SAS software (SAS Institute, Cary, NC) using PROC MIXED (Singer 1998). This procedure has the flexibility to handle repeated-measures data sets in which some subjects were not tested under every condition. Paired comparisons were performed using the Tukey-Kramer procedure, maintaining a 0.05 significance level within each set of tests.

\section{RESULTS}

All six participants developed consistent responding under the second-order cocaine schedule (cocaine-plus-stimulus) within seven sessions. Under these conditions, subjects completed an average of 109.2 units of the 100-response FR requirement during each session, totaling well over 10000 responses per session at a rate of about 1.2 responses per second. In three of the six participants, positively accelerated patterns of responding developed, with a pause at the start of each 1-h interval, followed by a rapid acceleration in responding that continued until cocaine was delivered at the end of the 1-h interval. This pattern developed gradually over sessions and produced cumulative response records with a scalloped appearance. For example, the cumulative records seen in Figure 1 show that subject $\mathrm{H}-743$ responded at high, steady rates during initial sessions (Figure 1a), but developed scalloped response patterns gradually over time. The three participants who did not develop scalloped response patterns continued to have high response rates throughout the 1-h intervals.

\section{Conditioned Reinforcing Effects of the Brief Stimulus}

Responding was maintained when cocaine was available, regardless of whether the brief stimulus was presented (Figure 2a). However, the effects of the brief stimulus were clearly seen under the placebo conditions, where responding was only maintained when the brief stimulus was presented. Within sessions (Figure $2 \mathrm{~b}$ ), responding differed across the three fixed-interval components of the session under saline conditions, but not cocaine conditions. When the brief stimulus was presented during saline sessions, responding was maintained in the first interval at rates comparable to those seen during cocaine sessions, but responding decreased by about $50 \%$ in the second and third intervals. When the stimulus was not presented during 


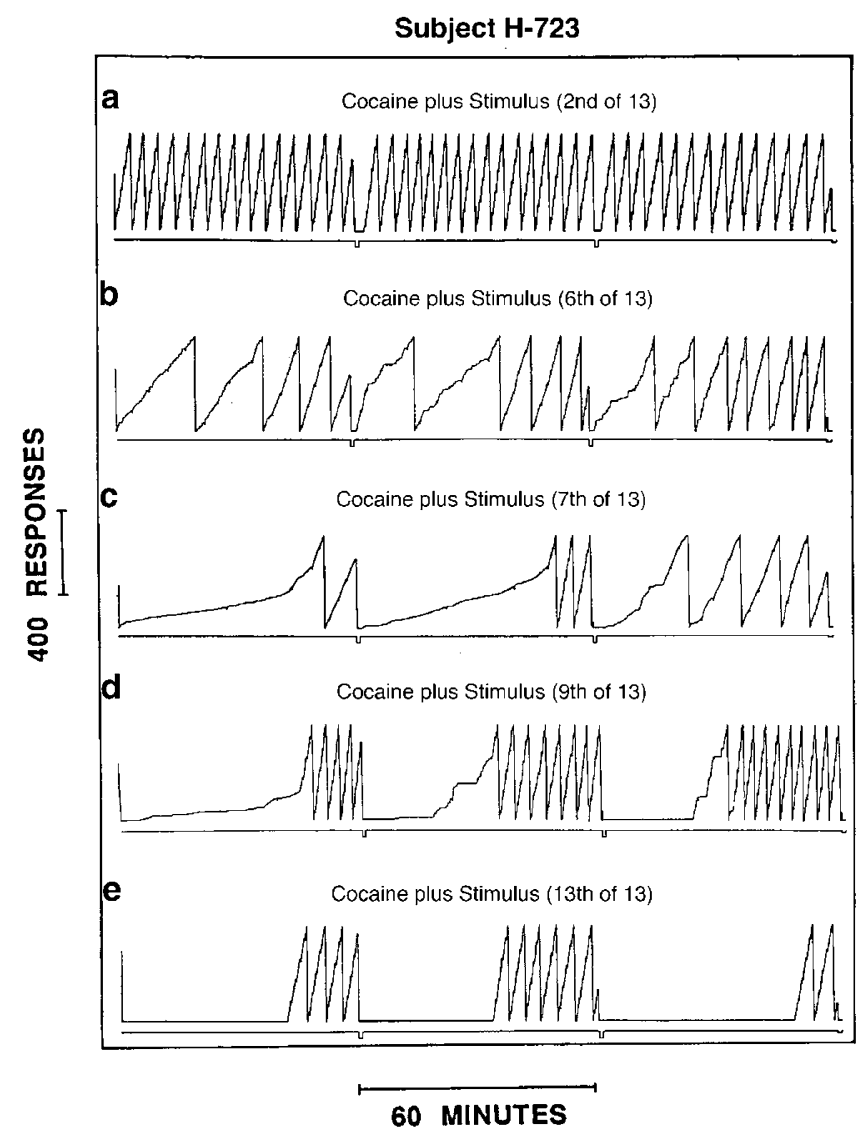

Figure I Cumulative-response records of subject $\mathrm{H}-743$ under baseline conditions, showing the development of scalloped patterns of responding over 13 sessions. Every 100th lever pull produced a brief stimulus ( $2 \mathrm{~s}$ ), and the first stimulus produced after I $\mathrm{h}$ was longer $(\mathrm{I} 0 \mathrm{~s})$ and accompanied by an injection of cocaine, indicated by a pip on the lower line of the record. Responding initially occurred at a high and steady rate (second session (a)). By the sixth and seventh sessions (b, c), a gradual acceleration across the interval became apparent. During later sessions, (ninth and I 3th sessions (d, e)), there was a long latency to begin responding during each interval, after which responding was maintained at a high and steady rate until cocaine was delivered.

saline sessions, there was a slight (nonsignificant, $P>0.74$ ) reduction in responding during the first interval, but responding was dramatically reduced in the second and third intervals.

A striking example of the conditioned reinforcement exhibited by the brief stimulus can be seen in Figure 3 . When cocaine and the brief stimulus were both discontinued during the first of seven 'Saline No-Stimulus' sessions (Figure $3 \mathrm{~b}$ ), the responding of subject $\mathrm{H}-723$ decreased during the first hour, prior to receiving any injections. After receiving the first saline injection under this condition, responding was virtually eliminated for this subject. When brief stimulus presentations were reinstituted (during the first of five 'Saline-Plus-Stimulus' sessions, depicted in Figure 3d), responding quickly returned to near-baseline levels and was sustained through the session, even though cocaine was still withheld. This stimulusmaintained responding continued for five sessions, until stimulus presentations were again discontinued (in the first of three 'Saline No-Stimulus' sessions, depicted in Figure 3f) and responding abruptly decreased.
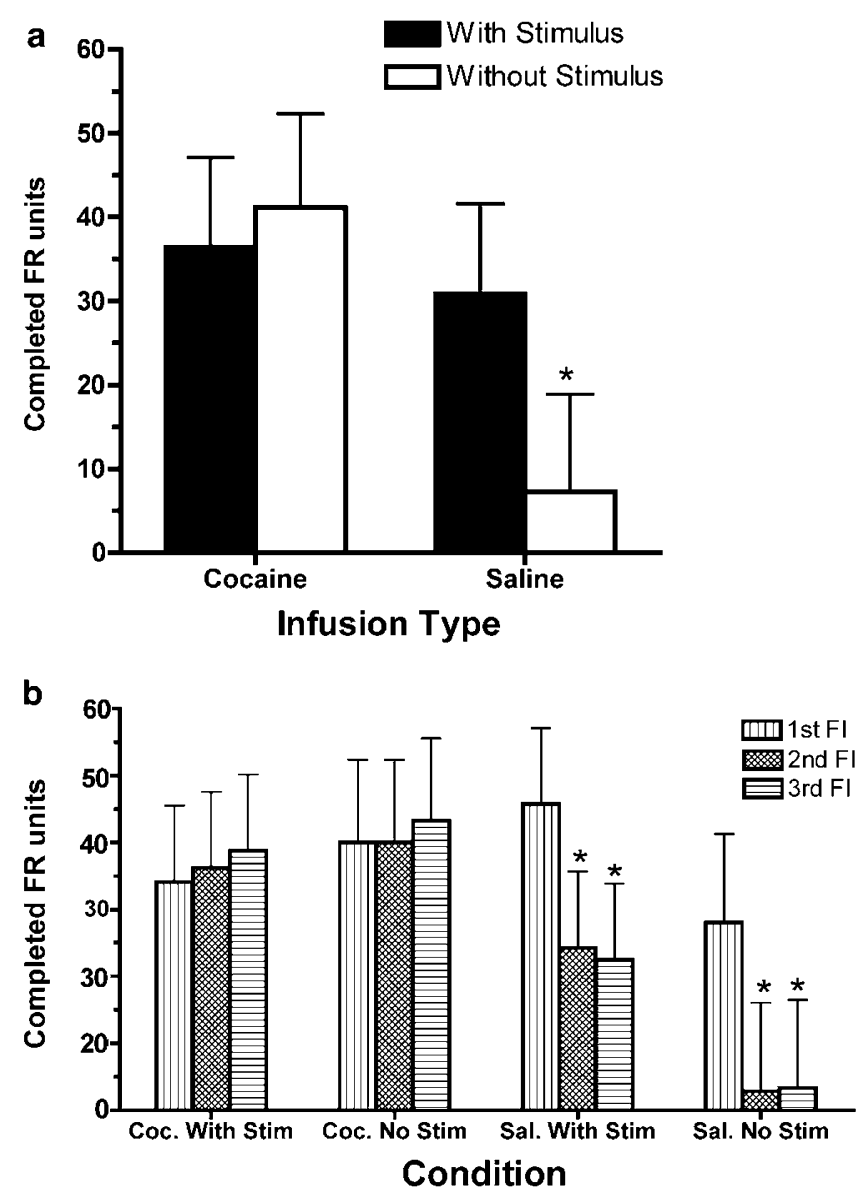

Figure 2 Mean number of 100-response fixed-ratio units completed under cocaine and saline conditions with and without the brief stimulus (with SEM indicated by error bars). This measure is customarily used to quantify responding under second-order schedules, where each ratio is considered a unit. The number of completed units is averaged across the three fixed intervals of the session in (a). Statistical analysis revealed that the interaction of injection type $\times$ stimulus condition was significant $(F(I, 34)=14.46, P<0.05)$. The asterisk indicates that the number of units completed under the saline condition without the brief stimulus was significantly lower than under each of the other three conditions in the panel $(P<0.05)$. (b) Fixed-ratio units completed during each of the three fixed intervals (each lasting I h). The asterisks indicate that, under saline conditions, significantly fewer ratios were completed during the second and third fixed intervals with the brief stimulus than in the first interval with the stimulus, and significantly fewer ratios were completed during the second and third fixed intervals without the brief stimulus than in each of the cocaine conditions, as well as the first interval under saline with the stimulus $(P<0.05)$.

\section{Patterns of Responding}

A complete understanding of behavior involves analyzing not only rates, but also patterns of responding. These patterns reveal the sensitivity of behavior to the contingencies that exist in the environment. Specific schedules of reinforcement tend to produce characteristic response patterns that are similar across different individuals, reinforcing events, and even species (eg see Skinner, 1956; Goldberg et al, 1975). In animals trained with FI schedules, responding typically accelerates over the interval until the reinforcer is delivered, indicating a sensitivity to the increasing likelihood of reinforcement as the interval of time elapses. As seen in the example presented in Figure 1, 
Subject H-743

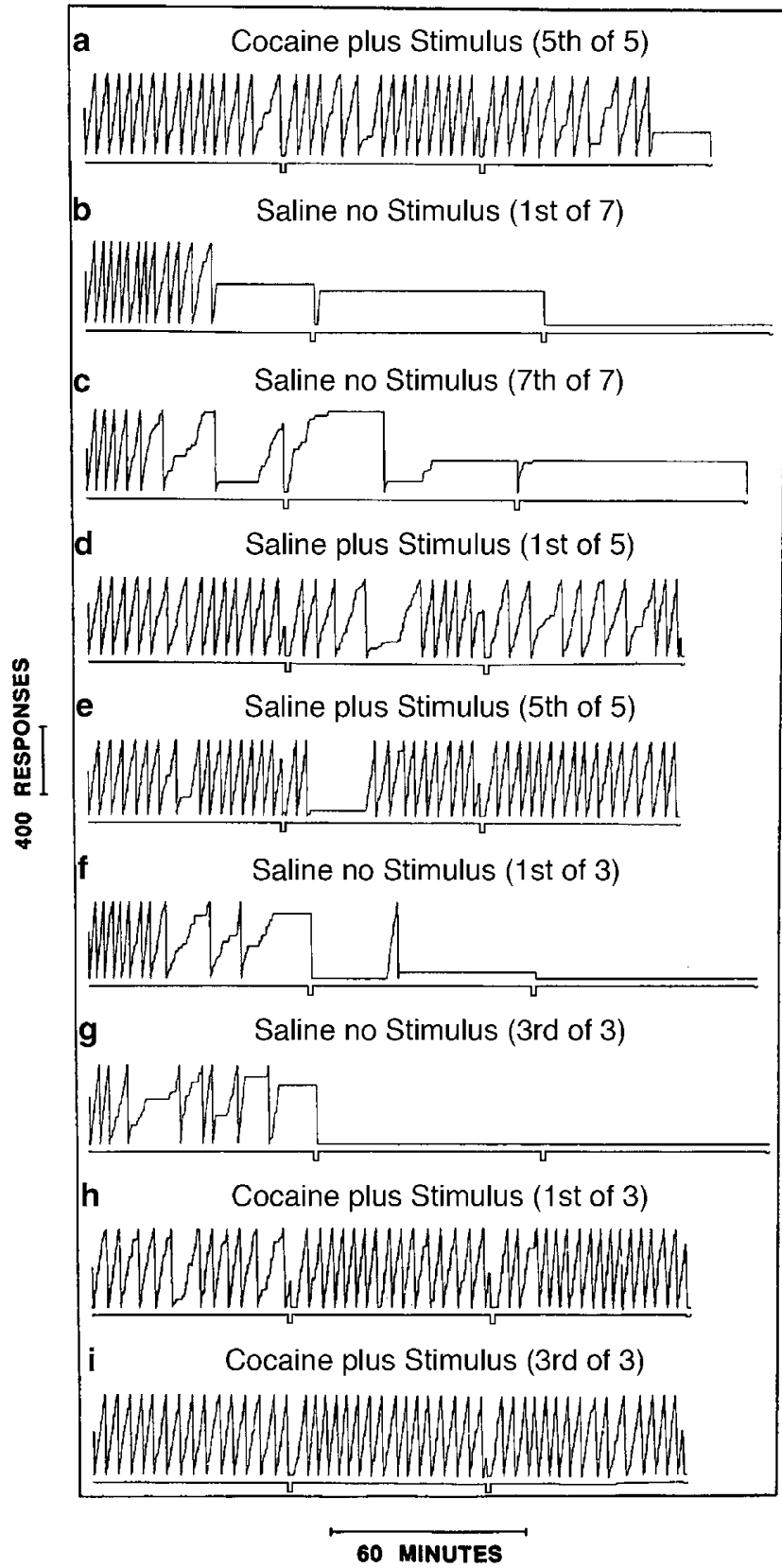

Figure 3 Cumulative-response records of subject $\mathrm{H}-723$ under baseline conditions (ie cocaine with the brief stimulus) and during extinction with and without the brief stimulus. High rates of responding were maintained during the cocaine-plus-stimulus condition (fifth session of this condition, shown in (a)), but responding quickly dropped during the first session in which cocaine and the stimulus were discontinued (saline no-stimulus (b)). After the seventh session with saline and no-stimulus (c), responding was reinstated when the stimulus was again presented, but cocaine was still withheld (saline-plus-stimulus (d)). The stimulus continued to maintain responding over five consecutive saline-plus-stimulus sessions (fifth session of this condition (e)), but responding again dropped quickly when the stimulus was discontinued (first and third sessions of second replication with saline no-stimulus $(f, g)$ ). Finally, responding quickly returned to baseline rates when both cocaine and the stimulus were presented (first and third sessions of second replication of the baseline cocaine-plusstimulus condition $(h, i))$. this pattern of acceleration developed in some of the subjects in this study. Acceleration over the interval can be formally quantified as quarter life, the percentage of the interval that passes before $25 \%$ of the responses in that interval are emitted. If there were no acceleration, the quarter life would be 25 . If responding accelerated or decelerated over the interval, the quarter life would be greater than or less than 25 , respectively. On average, the quarter life was about 50 under all four conditions, indicating that responding accelerated over the interval (Figure 4a). Three of the six subjects exhibited robust scalloping under the cocaine with stimulus condition (quarter-life values of 59.3, 78.6, and 87.2\%), and the other three tended to have high response rates throughout the interval (quarter-life values of 23.3, 24.5, and 26.0\%). The same subjects that showed scalloping under the cocaine with stimulus conditions also showed scalloping under the other conditions.

Another way to quantify response patterns is to analyze two factors that determine the overall rate of responding during each fixed interval. These are (1) the latency to initiate responding in the interval and (2) the rate of responding during each FR100 component once responding has begun ('run rate'). This analysis indicated that the decreases in overall response rates when neither cocaine nor the brief stimulus were presented (see Figure 2) were not due to changes in latency to the first response (ie pausing at the start of the fixed-interval period). This latency measure was variable between subjects and did not differ significantly between the four conditions $(P>0.3)$. In contrast, the run rate measure (Figure $4 \mathrm{~b}$ ) indicated that responding was significantly reduced in the saline condition when the stimulus was not presented. Thus, the reduction in total responding in the saline without stimulus condition can be attributed to a lower rate of responding once responding had begun during each fixed-interval component, rather than to increased latency to begin responding.

\section{Subjective and Cardiovascular Effects}

Subjective ratings of positive and negative effects immediately following self-administered injections of cocaine or saline are presented in Figure 5. Cocaine was consistently rated as exclusively positive, and saline was rated as neither positive nor negative. Presentation of the brief stimulus did not significantly affect subjective ratings. Cocaine injections consistently increased heart rate (Figure 6), while saline did not.

At the end of each session, other self-rating measures were obtained, and cigarette smoking was monitored for $1 \mathrm{~h}$. In agreement with the subjects' ratings of positive drug effects obtained after each cocaine injection, the postsession questionnaires (ARCI and SDQ) indicated that the effects of 25-mg injections of cocaine were reliably different from placebo injections (see Figure 7). On the SDQ, cocaine injections produced elevated scores relative to placebo on the Feel Drug, Drug Liking, and Gut Sensations items (see Figure $7 \mathrm{a}$ ). On the ARCI, cocaine produced higher ratings than saline on both the MBG and LSD scales, but not the PCAG scale (see Figure 7b). Cigarette consumption was significantly increased during the 1 -h period of measurement after cocaine self-administration sessions compared to 

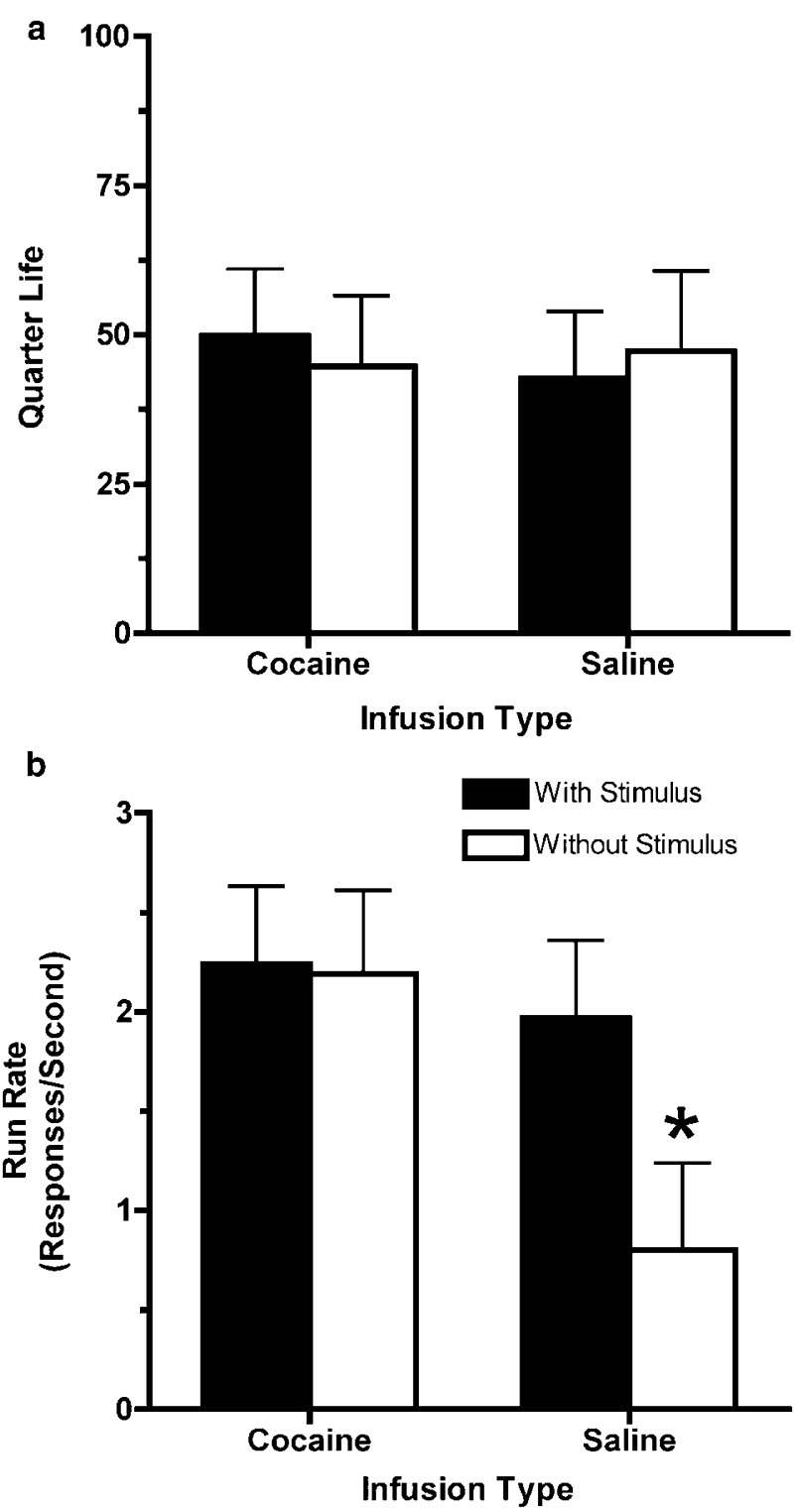

Figure 4 (a) Mean quarter-life values (with SEM indicated by error bars). This measure quantifies changes in responding during the fixed interval, with values higher than 25 indicating acceleration over the interval. Quarter life did not differ significantly across the four conditions $(P>0.6)$. (b) Run rate as a function of stimulus condition and injection type. This measure quantifies the response rate after the first response in each 100-response fixed-ratio component (ie, disregarding any pauses following stimulus presentations). The interaction of injection type $\times$ stimulus condition was significant $(F(I, 34)=8.96, P<0.05)$ for run rate, and the asterisk indicates that run rates in the saline condition without the brief stimulus were significantly lower than in each of the other three conditions in the panel $(P<0.05)$.

saline sessions (Figure 7c). This effect was observed in each of the six subjects.

It is interesting to note that both cardiovascular effects (Figure 8a) and subjective ratings of positive effects (Figure $8 \mathrm{~b}$ ) tended to decline within sessions across the three injections, but these declines were not statistically significant. The second and third injections of cocaine produced an increase in heart rate that was only about $60 \%$ as large as the increase produced by the first cocaine
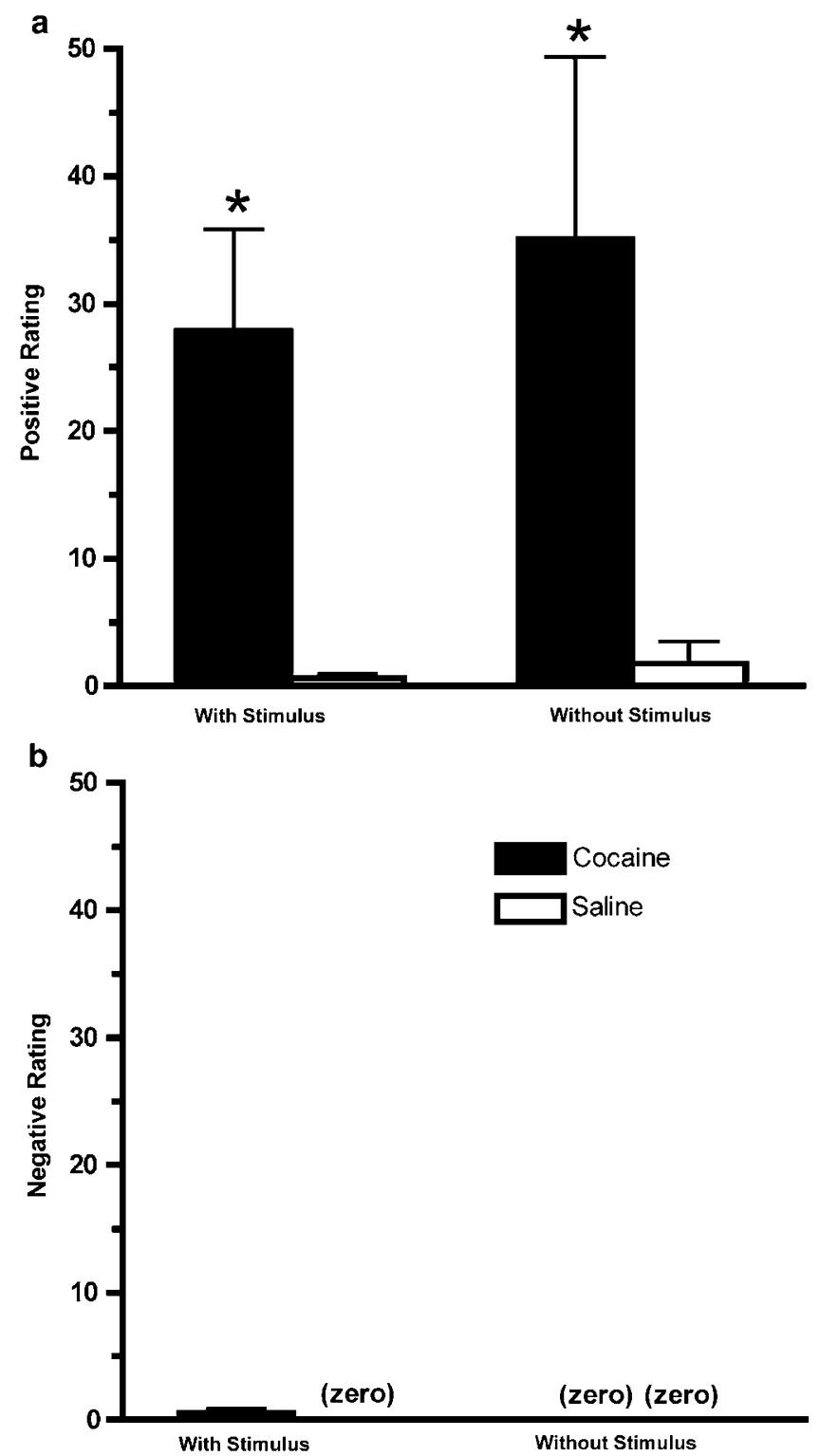

Figure 5 Positive (a) and negative (b) subjective ratings on $100 \mathrm{~mm}$ visual line analog scales immediately following injection with cocaine or saline. Injection type (cocaine vs saline) had a significant effect on positive ratings $(F(I, 30)=60.97, P<0.05)$, but there were no significant difference in negative ratings (all $P>0.27$ ). The asterisks indicate that positive ratings with cocaine were significantly higher than saline $(P<0.05)$.

injection of the day. Ratings of liking after the second injection were about $88 \%$ of scores after the first injection and scores after the third injection were about $80 \%$ of scores after the first injection.

\section{DISCUSSION}

Through experience with the second-order schedule of cocaine self-administration, the brief stimulus became a conditioned reinforcer in these human volunteers, maintaining thousands of drug-seeking responses when cocaine was not available. However, these reinforcing effects of the stimulus appear to have been overshadowed during periods when cocaine was available. That is, when cocaine was being 


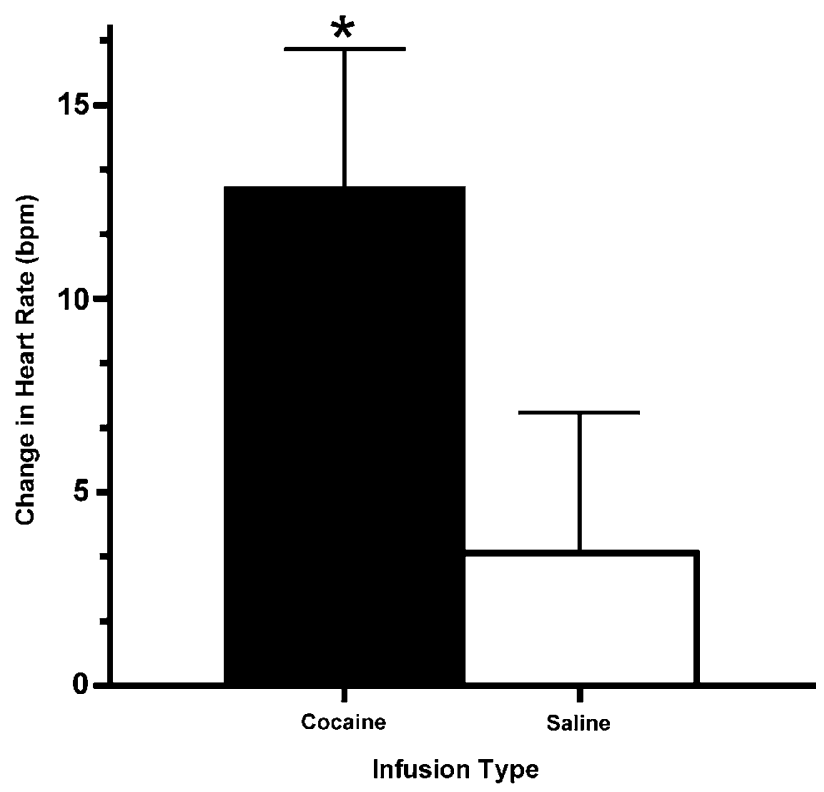

Figure 6 Change in heart rate (beats/minute) immediately following injection with cocaine or saline (rate following injection minus rate prior to injection). Heart rate data were only collected during cocaine with stimulus and saline with stimulus conditions. The asterisk indicates that cocaine significantly increased heart rate (ie the change was greater than zero; $P<0.05)$, but saline did not $(P>0.35)$.

received, the addition of brief stimulus presentations did not consistently increase responding beyond that maintained by cocaine alone. Thus, responding of these human volunteers was robustly maintained by presentation of cocaine, the cocaine-paired stimulus, or both, but responding dropped substantially when neither cocaine nor the stimulus was presented. This suggests that the most important impact that environmental stimuli might have on drug abuse is to maintain drug seeking during periods of drug unavailability, when this behavior might otherwise cease. This conclusion supports the general approach of numerous clinical efforts to recognize the salient environmental stimuli involved in drug abuse and to reduce their effectiveness (Carter and Tiffany, 1999; Childress et al, 1993; Drummond et al, 1995; McLellan et al, 2000; O'Brien 2001).

The suggestion that drug-related stimuli might have the most impact during periods of drug unavailability is also relevant to distinctions between drug seeking and drug taking in second-order schedules (see Everitt and Robbins, 2000; Schindler et al, 2002). This distinction emphasizes the importance of analyzing responding that occurs prior to the delivery of the drug, either by focusing on responding during the first component of the session (eg Arroyo et al, 1998; Pilla et al, 1999), or by arranging the schedule parameters so that the drug is only delivered at the end of the session (eg Goldberg et al, 1976, 1981; Goldberg and Tang, 1977; Heishman et al, 2000, Katz, 1979; Kelleher and Goldberg, 1977). The results of the present study suggest that responding is more dependent on the brief stimulus during periods in which the drug is available than during periods when the drug is not available. That is, while responding tended to be maintained during the first interval in all four conditions, the response-enhancing effects of the
Post-session SDQ

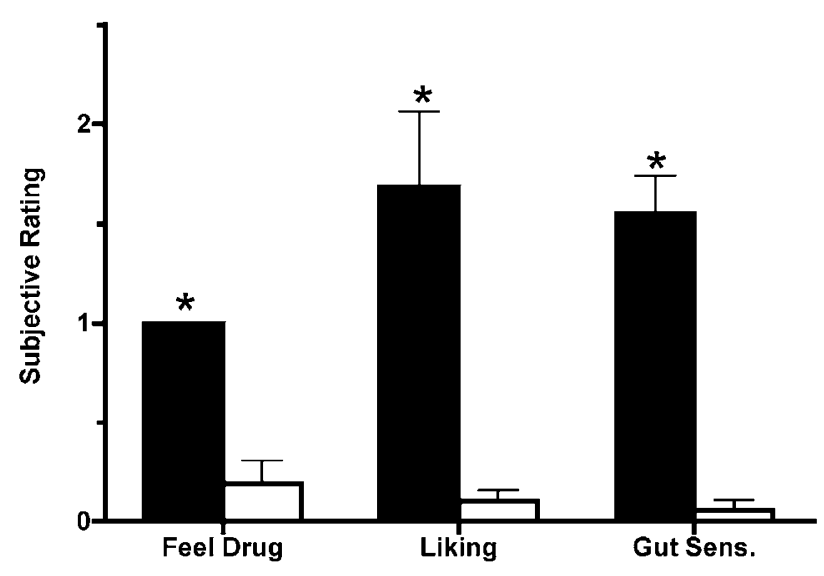

Questionnaire Item

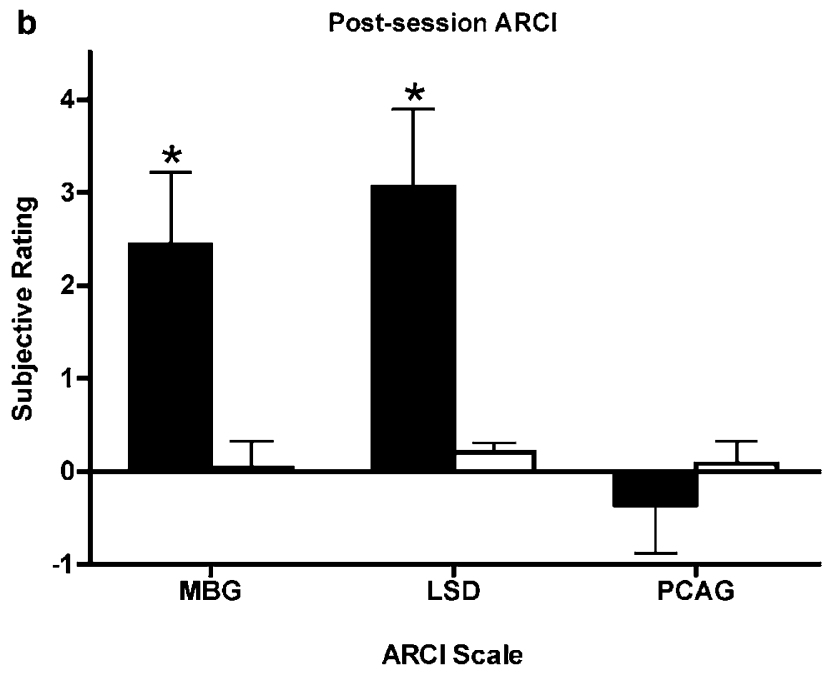

C Post-session Smoking

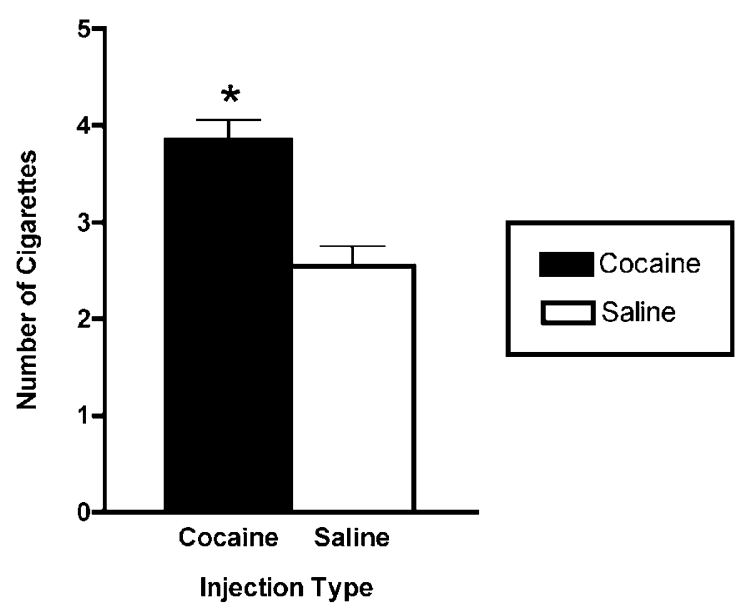

Figure 7 Post-session measures, including subjective ratings from questionnaires given at the end of each session, and levels of post-session cigarette smoking. (a) Subject ratings on the SDQ for the items, 'Feel Drug', 'Drug Liking', and 'Gut Sensations.' (b) Subject ratings on the ARCl scales MBG, LSD, and PCAG. (c) Mean number of cigarettes smoked during the first hour after cocaine and saline sessions. Asterisks indicate that all measures in the figure, except PCAG, were significantly higher after cocaine sessions than after saline sessions $(P<0.05)$. 

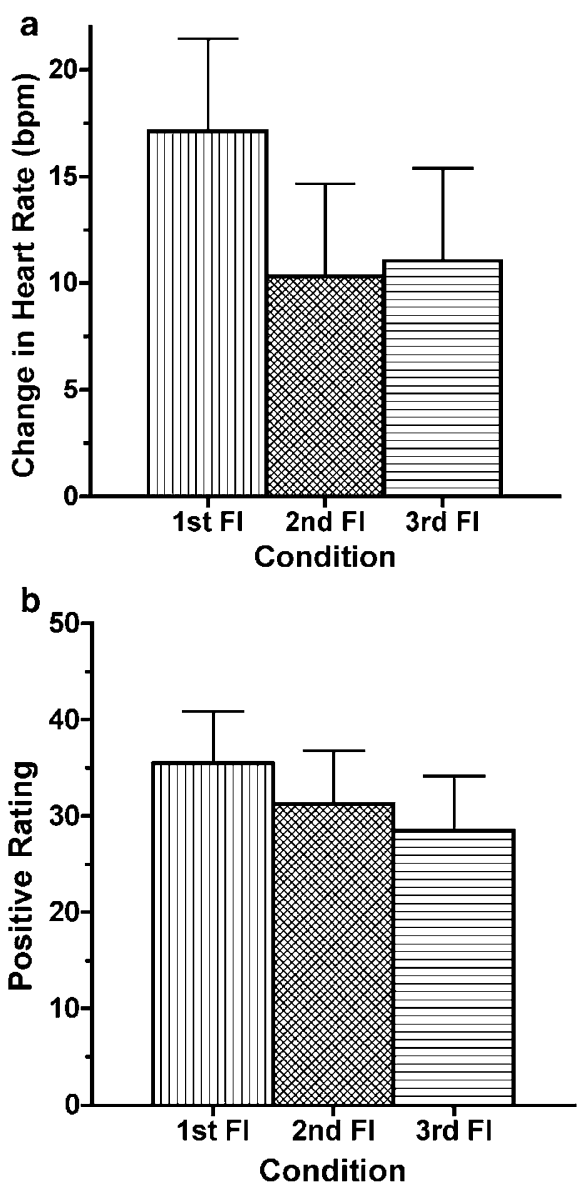

Figure 8 Heart rate change (a) and positive subjective ratings (b) after the first, second, and third cocaine injections of the session. Although these measures of drug effect decreased slightly after the first injection, these decreases were not statistically significant.

stimulus were most prominent under saline conditions during the second and third intervals (see Figure 3, panels c and d). These results suggest that drug seeking may be more sensitive than drug taking to the conditioned reinforcing effects of the brief stimulus. Alternatively, they may represent a greater effect of the stimulus on a normally low rate of responding. These results emphasize the importance of studying the effects of drug-related stimuli under a variety of conditions, including those when the drug is no longer available (see Kelleher and Goldberg, 1977; Goldberg et al, 1981; Arroyo et al, 1998; Spealman et al, 1999).

The power of drug-related environmental stimuli to maintain drug seeking even when cocaine is not available is most impressive, considering the fact that the human volunteers could clearly discriminate between drug and placebo injections. The questionnaire administered after each session indicated that cocaine produced a subjective profile of effects that were completely different from placebo, but typical of the profiles obtained in earlier studies where cocaine injection was not response-dependent (see Haertzen and Hickey, 1987). When questioned immediately following each injection, subjects consistently rated cocaine injections as positive and saline injections as neutral. Cocaine also produced immediate cardiovascular

effects that may have been discriminable to the subjects. Even though subjects were informed that injections would be either cocaine or placebo and that the second and third injections of each session would be the same as the first, they continued to respond at high rates for the second and third placebo injections when the brief stimulus was presented.

This stimulus-induced persistence of responding under placebo conditions represents a dissociation between selfadministration behavior and the subjective effects of the injection. This dissociation can be compared to dissociations found in other studies in which human subjects provided subjective ratings of the effects of self-administered drugs. In studies of morphine self-administration (Heishman et al, 2000; Lamb et al, 1991), low to moderate doses of morphine had reinforcing effects even though they were subjectively rated as neutral. In a study of intravenous nicotine self-administration, reinforcing doses of nicotine were subjectively rated as both positive and negative (Harvey et al, 2004). Thus, these studies provide three different demonstrations of dissociations between self-administration responding and the subjective effects of a drug. That is, drug seeking can be maintained when no drug is delivered (present study), when the dose has no subjective effect (morphine studies), or when the drug has aversive effects in addition to positive effects (nicotine study). In addition, the cocaine-paired stimulus maintained responding under placebo conditions in the present study, but it was not rated as subjectively positive (see Figure 5). These dissociations between self-administration responding and subjective effects clearly indicate that drug seeking and drug taking are not simply maintained by euphorigenic effects of the drug, or even by stimuli mimicking the euphorigenic effects of the drug. These results may be related to differences in the contingencies maintaining self-report and drug-seeking behavior, and they are also consistent with proposed differences in neuronal mechanisms underlying the euphoric ('drug liking') and reinforcing effects of abused drugs (eg Berridge and Robinson, 1998, 2003; Robinson and Berridge, 1993).

Most studies of the effects of drug-related stimuli in human subjects depend on conditioning that has occurred in the natural environment rather than in the laboratory. Unfortunately, not all subjects come into the laboratory with similar behavioral histories, and they may not react the same way to the stimuli used in the study. Foltin and Haney (2000) point out that another difficulty with studying stimuli established outside of the laboratory is that they may rapidly lose their effectiveness when presented without the drug. Subjects may quickly learn that, at least in the laboratory setting, the stimuli are no longer associated with cocaine. However, these problems can be overcome by associating arbitrary, neutral stimuli with drug administration in a controlled laboratory setting. This gives all subjects a similar history and maintains the effectiveness of the stimuli. This was accomplished in the present study and also in a study by Foltin and Haney (2000). In that study, previously neutral stimuli were associated with smoked cocaine in human subjects. These stimuli came to elicit physiological changes (eg increased heart rate), and they had subjective 
effects such as increased self-report of wanting cocaine during a period when the drug was no longer available. The cocaine-associated stimuli also functioned as conditioned reinforcers in a choice procedure, even though, like the present study, they did not produce positive subjective effects on their own.

Overall, the behavior of human subjects on the secondorder schedule of cocaine self-administration was similar to the behavior previously described in animals (Goldberg et al, 1990; Schindler et al, 2002). The ability of the brief stimulus to maintain responding during long periods when the drug is not available is a hallmark of the second-order schedule in animal studies. Unlike the present study, it has often been found with animals that the brief stimulus can increase responding substantially even when the availability of cocaine is maintained. This may have been prevented by a ceiling effect in the present study, where cocaine maintained high rates of responding even without the stimulus. The scalloped patterns of responding that developed in some subjects (as seen in Figure 1) closely resemble those obtained in squirrel and rhesus monkeys (Goldberg and Tang, 1977) and in rats (Arroyo et al, 1998). These similarities extend the findings of early studies with human subjects, where drug self-administration was found to be similar in humans and animals under less complex schedules of reinforcement with a variety of drugs of abuse (Griffiths et al, 1978).

In laboratory studies, human subjects working under fixed-interval schedules of reinforcement sometimes respond at high rates throughout the interval rather than in the scalloped response pattern typical of animals (for a more complete discussion of this issue, see reviews by Pierce and Cheney, 2004; Weiner, 1983). This apparent 'insensitivity' to the fixed-interval contingency, seen in three of the six participants in the present study, probably results from extensive histories of reinforcement outside the laboratory, as well as from verbal, rule-governed behavior (Lowe et al, 1983), which may be influenced by instructions given to the subjects during the study (Kerr and Keenan, 1997). In the present study, the instructions did not explicitly describe the fixed-ratio or fixed-interval contingencies. Therefore, the scalloped patterns of responding that developed in some subjects were a direct result of the contingencies themselves, rather than the instructions.

Cocaine (Roll et al, 1997), amphetamine (Schuster et al, 1979), and some other drugs of abuse (ethanol, heroin, and pentobarbital, but not marijuana) have been found to increase cigarette smoking in previous studies (see the review by Henningfield et al, 1996), and these effects appear to last about $1-3 \mathrm{~h}$ with cocaine (Radzius et al, 1997). In the present study, cigarette smoking increased in each subject during the hour following sessions in which cocaine rather than placebo was self-administered. This enhancement of smoking may reflect a synergistic increase in the reinforcing effects of cocaine and nicotine when they are combined, possibly due to the ability of these two drugs to increase dopamine overflow in the nuclueus accumbens by two different mechanisms (Gerasimov et al, 2000; Sziraki et al, 1999; Zernig et al, 1997).

Cocaine is often abused in 'binges', with repeated dosing over a limited period of time, followed by a period of abstinence. Such dosing regimens have been reported to lead to acute tolerance, with later doses in the series having less of an effect than earlier doses (see Schindler, 1996). Acute tolerance to both cardiovascular and subjective effects has been reported following intranasal (Fischman et al, 1985; Foltin and Haney, 2004), smoked, or intravenous (Foltin and Fischman, 1991) administration of cocaine. There was a suggestion of acute, within-session tolerance to both the cardiovascular and subjective effects of the second and third injections of cocaine in the present study, but these effects were not statistically significant. Regardless of whether these changes represent acute tolerance, it is clear that drug-seeking behavior did not change over the course of the session in the cocaine no-stimulus condition (Figure 2b), which indicates that acute tolerance did not develop to the reinforcing effects of cocaine.

The findings of this study have implications for understanding the persistent drug seeking that characterizes addiction to not only cocaine and other stimulants, but other drugs, such as opioids, alcohol, and nicotine. As discussed elsewhere (O'Brien, 2001), patterns of drug abuse and addiction are only partly explained by the direct actions of the drug itself. Other factors, including conditioned effects of drug-related stimuli, are important determinants of the onset and continuation of drug abuse, posing challenges to treatment and relapse prevention. For example, symptoms of tobacco withdrawal can be reduced by nicotine replacement therapy, but tobacco-associated stimuli can still precipitate powerful urges to smoke and lead to relapse after many years of smoking cessation (Shiffman et al, 2003). As indicated by the present study, even arbitrary stimuli associated with drug effects can powerfully influence drug-seeking behavior. Achieving a better understanding of the conditions under which these conditioned effects develop and persist, and how they can be counteracted, remains an important challenge for addiction researchers.

In this study, human subjects with a history of cocaine abuse self-administered intravenous cocaine in the laboratory under a second-order schedule, a procedure that has been used extensively as an animal model of drug abuse. Under these conditions, the ability of drug-related environmental stimuli to enhance the persistence of drug seeking was quite similar in human and animal subjects. These results suggest that second-order schedules can be used more extensively to study the ability of environmental stimuli to perpetuate drug-seeking behavior in human drug abusers. As this procedure focuses directly on behavioral control, it could provide a valuable complement to other measures, for example, in addition to or instead of selfreports of craving in brain imaging studies. The similarity of the results obtained with human and non-human subjects also supports the validity of second-order schedules of drug self-administration in animals as a preclinical model of human drug abuse. Finally, these results demonstrate that neutral stimuli can quickly acquire conditioned-reinforcing effects and strongly increase drug-seeking behavior in the absence of drug reinforcement. These findings strengthen the view that drug abuse is highly dependent on contextual stimuli and that detoxification (withdrawal of drug) alone would not be sufficient to successfully treat dependent individuals. 


\section{ACKNOWLEDGEMENTS}

This research was supported by the Intramural Research Program of the National Institute on Drug Abuse, National Institutes of Health, Department of Health and Human Services.

\section{REFERENCES}

Arroyo M, Markou A, Robbins TW, Everitt BJ (1998). Acquisition, maintenance and reinstatement of intravenous cocaine selfadministration under a second-order schedule of reinforcement in rats: effects of conditioned cues and continuous access to cocaine. Psychopharmacology 140: 331-344.

Berridge KC, Robinson TE (1998). What is the role of dopamine in reward: hedonic impact, reward learning, or incentive salience? Brain Res Brain Res Rev 28: 309-369.

Berridge KC, Robinson TE (2003). Parsing reward. Trends Neurosci 26: 507-513.

Carter BL, Tiffany ST (1999). Meta-analysis of cue-reactivity in addiction research. Addiction 94: 327-340.

Childress AR, Hole AV, Ehrman RN, Robbins SJ, McLellan AT, O'Brien CP (1993). Cue reactivity and cue reactivity interventions in drug dependence. NIDA Res Monogr 137: 73-79.

Di Ciano P, Everitt BJ (2003). Differential control over drugseeking behavior by drug-associated conditioned reinforcers and discriminative stimuli predictive of drug availability. Behav Neurosci 117: 952-960.

Drummond DS, Tiffany ST, Glautier S, Remington B (eds) (1995). Addictive Behaviour: Cue Exposure Theory and Practice. Wiley and Sons, West Sussex: England, 246 pp.

Everitt BJ, Robbins TW (2000). Second-order schedules of drug reinforcement in rats and monkeys: measurement of reinforcing efficacy and drug-seeking behaviour. Psychopharmacology 153: 17-30.

Fischman MW, Schuster CR, Javaid J, Hatano Y, Davis J (1985). Acute tolerance development to the cardiovascular and subjective effects of cocaine. J Pharmacol Exp Ther 235: 677-682.

Foltin RW, Fischman MW (1991). Smoked and intravenous cocaine in humans: acute tolerance, cardiovascular and subjective effects. J Pharmacol Exp Ther 257: 247-261.

Foltin RW, Haney M (2000). Conditioned effects of environmental stimuli paired with smoked cocaine in humans. Psychopharmacology 149: 24-33.

Foltin RW, Haney M (2004). Intranasal cocaine in humans: acute tolerance, cardiovascular and subjective effects. Pharmacol Biochem Behav 78: 93-101.

Fraser HF, van Horn GD, Martin WR, Wolbach AB, Isbell H (1961). Methods for evaluating addiction liability. (A) 'Attitude' of opiate addicts toward opiate-like drugs, (B) A short-term 'direct' addiction test. J Pharmacol Exp Ther 133: 371-387.

Gerasimov MR, Franceschi M, Volkow ND, Rice O, Schiffer WK, Dewey SL (2000). Synergistic interactions between nicotine and cocaine or methylphenidate depend on the dose of dopamine transporter inhibitor. Synapse 38: 432-437.

Goldberg SR (1973). Comparable behavior maintained under fixed-ratio and second-order schedules of food presentation, cocaine injection or $\mathrm{d}$-amphetamine injection in the squirrel monkey. J Pharmacol Exp Ther 186: 18-30.

Goldberg SR, Kelleher RT, Goldberg DM (1981). Fixed-ratio responding under second-order schedules of food presentation or cocaine injection. J Pharmacol Exp Ther 218: 271-281.

Goldberg SR, Kelleher RT, Morse WH (1975). Second-order schedules of drug injection. Fed Proc 34: 1771-1776.

Goldberg SR, Morse WH, Goldberg DM (1976). Behavior maintained under a second-order schedule by intramuscular injection of morphine or cocaine in rhesus monkeys. J Pharmacol Exp Ther 199: 278-286.
Goldberg SR, Schindler CW, Lamb RJ (1990). Second-order schedules and the analysis of human drug-seeking behavior. Drug Dev Res 20: 217-229.

Goldberg SR, Spealman RD, Kelleher RT (1979). Enhancement of drug-seeking behavior by environmental stimuli associated with cocaine or morphine injections. Neuropharmacology 18: 1015-1017.

Goldberg SR, Tang AH (1977). Behavior maintained under second-order schedules of intravenous morphine injection in squirrel and rhesus monkeys. Psychopharmacology 51: 235-242.

Griffiths RR, Bigelow GE, Liebson I (1978). Experimental drug selfadministration: generality across species and type of drug. NIDA Res Monogr 20: 24-43.

Haertzen CA, Hickey JE (1987). Addiction Research Center Inventory (ARCI): measurement of euphoria and other drug effects. In: Bozarth MA (ed). Methods of Assessing the Reinforcing Properties of Abused Drugs. Springer-Verlag: New York. pp 489-524.

Harvey DM, Yasar S, Heishman SJ, Panlilio LV, Henningfield JE, Goldberg SR (2004). Nicotine serves as a robust reinforcer of intravenous drug-taking behavior in human cigarette smokers. Psychopharmacology 175: 134-142.

Heishman SJ, Schuh KJ, Schuster CR, Henningfield JE, Goldberg SR (2000). Reinforcing and subjective effects of morphine in human opioid abusers: effect of dose and alternative reinforcer. Psychopharmacology 148: 272-280.

Henningfield JE, Keenan RM, Clarke PBS (1996). Nicotine. In: Schuster CR and Kuhar MJ (eds) Handbook of Experimental Pharmacology. Springer-Verlag: Berlin. pp 271-314.

Katz JL (1979). A comparison of responding maintained under second-order schedules of intramuscular cocaine injection or food presentation in squirrel monkeys. J Exp Anal Behav 32: 419-431.

Kelleher RT (1966). Conditioned reinforcement in second-order schedules. J Exp Anal Behav 9: 475-485.

Kelleher RT (1975). Characteristics of behavior controlled by scheduled injections of drugs. Pharmacol Rev 27: 307-323.

Kelleher RT, Goldberg SR (1975). Control of drug-taking behavior by schedules of reinforcement. Pharmacol Rev 27: 291-299.

Kelleher RT, Goldberg SR (1977). Fixed-interval responding under second-order schedules of food presentation or cocaine injection. J Exp Anal Behav 28: 221-231.

Kerr KPJ, Keenan M (1997). Rules and rule-governance: new directions in the theoretical and experimental analysis of human behaviour. In: Dillenburger K, O'Reilly MF (eds). Advances in Behaviour Analysis. University College Dublin Press: Dublin. pp 205-226.

Lamb RJ, Preston KL, Schindler CW, Meisch RA, Davis F, Katz JL et al (1991). The reinforcing and subjective effects of morphine in post-addicts: a dose-response study. J Pharmacol Exp Ther 259: 1165-1173.

Lowe FC, Beasty A, Bentall RP (1983). The role of human verbal behavior in human learning: infant performance on fixedinterval schedules. J Exp Anal Behav 39: 157-164.

Martin WR, Sloan JW, Sapira JD, Jasinski DR (1971). Physiologic, subjective, and behavioral effects of amphetamine, methamphetamine, ephedrine, phenmetrazine, and methylphenidate in man. Clin Pharmacol Ther 12: 245-258.

McLellan AT, Lewis DC, O'Brien CP, Kleber HD (2000). Drug dependence, a chronic medical illness: implications for treatment, insurance, and outcomes evaluation. JAMA 284: 1689-1695.

Mello NK, Mendelson JH (1985). Operant acquisition of marihuana by women. J Pharmacol Exp Ther 235: 162-167.

Mello NK, Mendelson JH, Kuehnle JC, Sellers MS (1981). Operant analysis of human heroin self-administration and the effects of naltrexone. J Pharmacol Exp Ther 216: 45-54. 
Mello NK, Mendelson JH, Palmieri S, Lex BW, Teoh SK. (1990). Operant acquisition of alcohol by women. J Pharmacol Exp Ther 253: 237-245.

O'Brien CP (2001). Drug Addiction and Drug Abuse. In: Hardman JG, Limbird LE, Gilman A (eds). Goodman and Gilman's The Pharmacological Basis of Therapeutics, 10th edn. McGraw-Hill: New York. pp 621-642.

O'Brien CP, Childress AR, McLellan AT, Ehrman R (1992). Classical conditioning in drug-dependent humans. Ann NY Acad Sci 654: 400-415.

Pierce WD, Cheney CD (2004). Behavior Analysis and Learning. Lawrence Erlbaum Associates: Mahwah, NJ, 528pp.

Pilla M, Perachon S, Sautel FO, Garrido F, Mann A, Wermuth CG et al (1999). Selective inhibition of cocaine-seeking behaviour by a partial dopamine D3 receptor agonist. Nature 400: 371-375.

Radzius A, Carriero NJ, Weinhold LL, Gorelick DA, Henningfield JE (1997). Changes in cigarette smoking not observed following repeated cocaine self-administration. Exp Clin Psychopharmacol 5: $51-53$.

Robinson TE, Berridge KC (1993). The neural basis of drug craving: an incentive-sensitization theory of addiction. Brain Res Brain Res Rev 18: 247-249.

Roll JM, Higgins ST, Tidey J (1997). Cocaine use can increase cigarette smoking: evidence from laboratory and naturalistic settings. Exp Clin Psychopharmacol 5: 263-268.

Schindler CW (1996). Cocaine and cardiovascular toxicity. Addict Biol 1: 31-47.

Schindler CW, Panlilio LV, Goldberg SR (2002). Second-order schedules of drug self-administration in animals. Psychopharmacology 163: 327-344.

Schuster CR, Lucchesi BR, Emley GS (1979). The effects of d-amphetamine, meprobamate, and lobeline on the cigarette smoking behavior of normal human subjects. NIDA Res Monogr 23: 91-99.
Shiffman S, Shadel WG, Niaura R, Khayrallah MA, Jorenby DE, Ryan CF et al (2003). Efficacy of acute administration of nicotine gum in relief of cue-provoked cigarette craving. Psychopharmacology 166: 343-350.

Shulman GD (1989). Experience with the cocaine trigger inventory. Adv Alcohol Subst Abuse 8: 71-85.

Singer JD (1998). Using SAS PROC MIXED to fit multilevel models, hierarchical models, and individual growth models. J Ed Behav Stat 24: 323-355.

Skinner BF (1956). A case history in scientific method. Am Psychol 11: 221-233.

Spealman RD, Barrett-Larimore RL, Rowlett JK, Platt DM, Khroyan TV (1999). Pharmacological and environmental determinants of relapse to cocaine-seeking behavior. Pharmacol Biochem Behav 64: 327-336.

Stewart J, de Wit H, Eikelboom R (1984). Role of unconditioned and conditioned drug effects in the self-administration of opiates and stimulants. Psychol Rev 91: 251-268.

Sziraki I, Sershen H, Benuck M, Hashim A, Laitha A (1999). Differences in receptor system participation between nicotineand cocaine-induced dopamine overflow in nucleus accumbens. Ann NY Acad Sci 877: 800-802.

Wallace BC (1989). Psychological and environmental determinants of relapse in crack cocaine smokers. J Subst Abuse Treatment 6: 95-106.

Weiner H (1983). Some thoughts on discrepant human-animal performances under schedules of reinforcement. Psych Record 33: $521-532$.

Wikler A (1973). Dynamics of drug dependence. Implications of a conditioning theory for research and treatment. Arch Gen Psychiatry 28: 611-616.

Zernig G, O'Laughlin IA, Fibiger HC (1997). Nicotine and heroin augment cocaine-induced dopamine overflow in nucleus accumbens. Eur J Pharmacol 337: 1-10. 